\title{
Correction to: Utilization of atmospheric solids analysis probe mass spectrometry for analysis of fatty acids on seed surface
}

\author{
Monika Cechová ${ }^{1}$ • Iveta Hradilová ${ }^{2}$ - Petr Smýkal ${ }^{2} \cdot$ Petr Barták $^{1}$ • Petr Bednáŕ ${ }^{1}$ \\ Published online: 14 May 2019 \\ (C) Springer-Verlag GmbH Germany, part of Springer Nature 2019
}

\section{Correction to: Anal Bioanal Chem https://doi.org/10.1007/s00216-018-1551-3}

The authors would like to call the reader's attention to the following correction in the section "Semiquantitative analysis", page 1176, of the original publication.

\section{Original sentence is:}

"For instance, the seeds of dormant L100 genotype are smaller, but their seed coats are relatively thick (average diameter of seed calculated from six individuals was $46.73 \mathrm{~mm}$, average outer seed coat area $32,160 \mathrm{~mm}^{2}$, and weight $102.2 \mathrm{mg}$ ). The seeds of non-dormant Cameor genotype are larger (The average seed diameter was $79.17 \mathrm{~mm}$, the average area $107,640 \mathrm{~mm}^{2}$, and weight $115.5 \mathrm{mg} . "$

The error is in the location of the decimal point of average diameter and average area of seeds that should be ten times lower for average diameter and one hundred times lower for average area.
The online version of the original article can be found at https://oi.org/ $10.1007 / \mathrm{s} 00216-018-1551-3$

Petr Bednář

petr.bednar@upol.cz

1 Regional Centre of Advanced Technologies and Materials, Department of Analytical Chemistry, Faculty of Science, Palacký University, 17. Listopadu 12, 77146 Olomouc, Czech Republic

2 Department of Botany, Faculty of Science, Palacký University, Šlechtitelů 27, 78371 Olomouc, Czech Republic

\section{Corrected sentence is:}

"For instance, the seeds of dormant L100 genotype are smaller, but their seed coats are relatively thick (average diameter of seed calculated from six individuals was $4.673 \mathrm{~mm}$, average outer seed coat area $321.6 \mathrm{~mm}^{2}$, and weight $102.2 \mathrm{mg}$ ). The seeds of non-dormant Cameor genotype are larger (the average seed diameter was $7.917 \mathrm{~mm}$, the average area $1076.4 \mathrm{~mm}^{2}$, and weight $115.5 \mathrm{mg}$."

Consequently, the range of $y$-axis of Fig. $5 b, d$ is changed. The range of $y$-axis in Fig. $5 b$ is $0.00-0.30$ and in Fig. $5 \mathrm{~d}$ is $0.00-1.60$. The correct Fig. $5 \mathrm{~b}, \mathrm{~d}$ is given below.

This error did not influence other results presented in the article. 
a

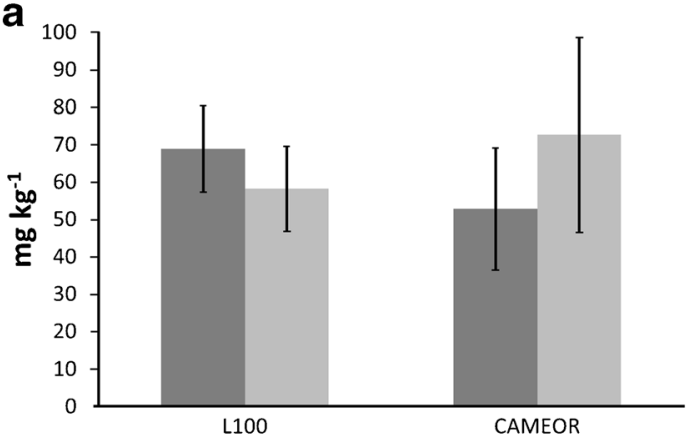

C

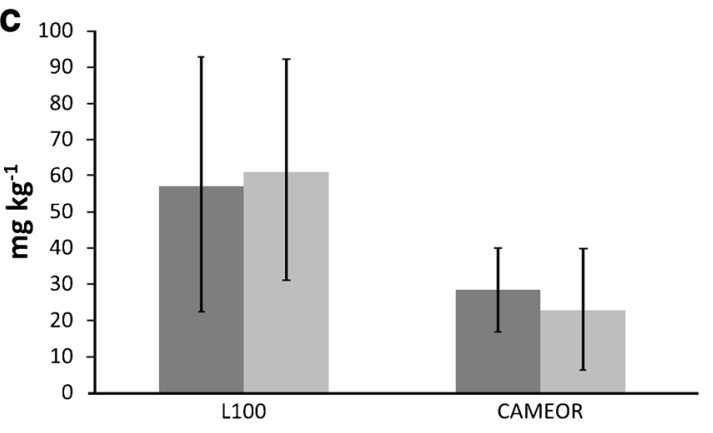

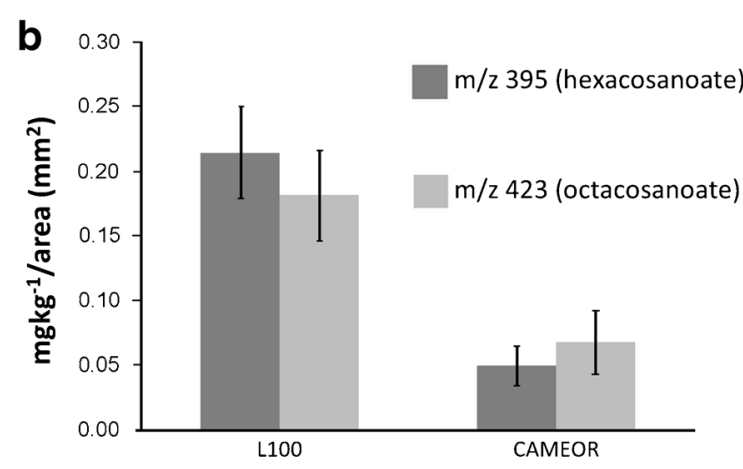

d

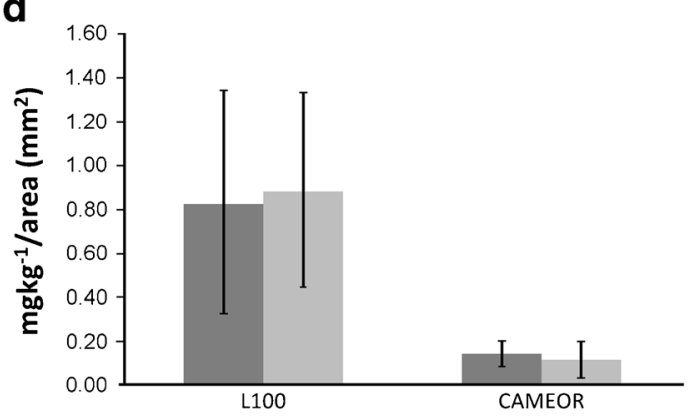

Fig. 5 Content of hexacosanoic and octacosanoic acid in L100 and Cameor seed coats (determined in hexane extracts of seed coats (a, b) and directly by the measurement of dry seed coats $(\mathbf{c}, \mathbf{d})$; related to weight of seed coat $(\mathbf{a}, \mathbf{c})$ and related to its surface area $(\mathbf{b}, \mathbf{d}))$

Publisher's note Springer Nature remains neutral with regard to jurisdictional claims in published maps and institutional affiliations. 